\title{
Educação Física Escolar: estado da arte e direções futuras
}

\author{
Mauro BETTI* \\ Osvaldo Luiz FERRAZ \\ Luiz Eduardo Pinto Basto Tourinho DANTAS** \\ *Faculdade de Ciên- \\ cias, Universidade Es- \\ tadual Paulista-Bauru. \\ **Escola de Educa- \\ ção Física e Esporte, \\ Universidade de São \\ Paulo.
}

\section{Resumo}

0 objetivo deste artigo é caracterizar e problematizar a Educação Física Escolar como prática profissional e subárea de pesquisa no campo mais amplo da Educação Física e das investigações educacionais. Para tal, inicialmente delimita o que é pesquisa em Educação Fisica Escolar, distinguindo-a da pesquisa sobre Educação Física Escolar, e quais seriam os objetos e hipóteses de pesquisa significativos para esta subárea. A seguir, analisa 289 artigos caracterizados como pesquisa em Educação Física Escolar, publicados em 11 periódicos (revistas) brasileiras, classificando-os nas categorias "ciclo de escolarização", "prática corporal "e "tema" investigados. Os resultados indicam que predominam os estudos no ensino fundamental, nas práticas "jogo" e "esporte", e pesquisas de cunho descritivo-interpretativo das aulas de Educação Física em várias dimensões e interrelações. Em conclusão, aponta a necessidade de maior direcionamento para as pesquisas nos âmbitos da didática, da implementação dos programas (currículos) formulados no bojo das políticas públicas, e da formação de professores. Por fim, alerta para a necessidade dos programas de pós-graduação em Educação Física no Brasil investirem mais nas pesquisas em Educação Física Escolar.

UnItermos: Educação física escolar; Profissão; Ensino; Pesquisa científica.

\section{Introdução}

Para abordar as áreas de atuação e investigação em Educação Física Escolar optamos neste artigo por discutir alguns pontos acerca da natureza da produção de conhecimento científico nesta subárea da Educação Física. Para isso, inicialmente, buscouse introduzir o entendimento dos autores acerca do fenômeno Educação Física Escolar. Em seguida, abordamos a temática da pesquisa em Educação Física Escolar a partir de quatro problemas: a) o que pode ser pesquisa em Educação Física Escolar; b) a pesquisa em Educação Física Escolar no campo mais amplo da pesquisa educacional; c) a produção bibliográfica em Educação Física Escolar a partir de periódicos científicos nacionais da área da Educação Física; d) possibilidades e necessidades de pesquisa em Educação Física Escolar.

Como muitas vezes o óbvio passa desapercebido, é oportuno relembrar que a construção da área Educação Física esteve desde seu início vinculada ao processo de escolarização e, ainda hoje, podemos dizer que Educação Física Escolar é inerente à Educação Física. $\mathrm{O}$ interesse na educação das crianças e jovens e a formação de professores está na base da institucionalização da Educação Física em muitos países. No Brasil, pelo menos desde a década de 30 é bem evidente a importância atribuída pelas políticas educacionais do governo federal à Educação Física, entendida esta como componente do currículo escolar (Bетті, 2009b). Atualmente, a Lei $n^{\circ}$ 9.394/1996, que estabelece as diretrizes e bases da educação brasileira, dispõe, em seu artigo 26 , que a Educação Física, "integrada à proposta pedagógica da escola, é componente curricular obrigatório da educação básica" (BRASIL, 1996), conforme nova redação dada pela Lei no 10.793/2003 (BRASIL, 2003).

Sem adentrar (embora reconhecendo sua pertinência) o longo debate sobre as diferenças entre "legalidade" e "legitimidade pedagógica" da Educação Física nos currículos escolares, conforme apresentado por vários autores (por exemplo, BRACHT, 1992), o fato é que, há longa data, no Brasil, as prescrições legais têm colocado a Educação Física Escolar no centro das oportunidades de trabalho e na formação dos profissionais da área. A despeito do crescimento e diversificação do mercado e da implementação dos 
cursos de bacharelado na área, raras instituições de ensino superior não mantém a modalidade "Licenciatura" na formação dos graduados em Educação Física.

Também no início da pós-graduação "stricto sensu" em Educação Física no Brasil, a Educação Física Escolar esteve presente. Por exemplo, no primeiro curso de pós-graduação da área de Educação Física, criado em 1977 na Universidade de São Paulo, o mestrando João Batista Freire da Silva defendeu dissertação intitulada "As relaçôes entre o fazer e o compreender na prática da Educação Física", a primeira do curso a utilizar a expressão "Educação Física" com o sentido de "componente curricular" da educação básica. A título de exemplo, a expressão "Educação Física Escolar" está presente nas ementas das áreas de concentração ou linhas de pesquisa nos três programas de pós-graduação mantidos pelas universidades públicas paulistas (USP, UNESP e UNICAMP) que estão inseridos na área de avaliação de Educação Física na CAPES. Embora minoritária, a pesquisa em Educação Física escolar é temática continuadamente presente em periódicos científicos especializados brasileiros, bem como na produção bibliográfica oriunda do corpo docente e discente de pelo menos 11 programas de pós-graduação "stricto sensu" da área (ROSA \& LETA, 2010, 2011).

Não há como não reconhecer a relação entre área da Educação Física e a Educação Física Escolar, mas o que é Educação Física Escolar? Há vários modos de defini-la. Preferimos fazê-lo a partir do que fazem (ou espera-se que façam) os professores de Educação Física na Escola.

E o que eles fazem? Elaboram, implementam e avaliam programas de ensino que tematizam, do ponto de vista didático-pedagógico, as brincadeiras e o jogos, o esportes, as lutas, as ginásticas, as danças, exercícios físicos, atividades rítmicas e etc., com propósitos educacionais explícitos e implícitos, quer dizer, com intenção de influenciar a formação dos sujeitos considerando que:

- A tematização didático-pedagógica faz-se a partir de sentidos culturais e potencialidades de estimulação do organismo humano que se apresentam naquelas manifestaçōes (brincadeira, jogo e etc.) ligadas à tradição da Educação Física, tradição esta que se renova (ou deve se renovar, sob pena de desatualizar-se) em consonância com os contextos sócio-históricos, que são mutáveis.

- Os propósitos e as direçóes imprimidos aos processos educacionais-escolares também mudam conforme mudam os contextos sócio-históricos ${ }^{2}$ (econômico, político, cultural, científico), as mentalidades e os interesses envolvidos. Espera-se que as mudanças nos propósitos e direções sejam acompanhadas das mudanças correlatas nas práticas escolares cotidianas, o que nem sempre acontece, ou muitas vezes acontece lentamente, ou de modo descompassado.

- Os sujeitos aos quais se dirigem os esforços educativos são crianças, jovens e adultos conduzidos à condição de alunos nos tempos/espaços de formatação escolar: educação infantil, ensino fundamental, ensino médio e educação de jovens e adultos.

- Os propósitos e as direções da formação dos alunos dizem respeito a modos de ser e conviver, de pensar e conhecer, de apreciar e usufruir, de agir.

Portanto, depreende-se que a Educação Física, como qualquer disciplina do currículo escolar, não pode ser analisada como um fenômeno "técnico", "neutro", independentemente dos tempos e espaços históricos e dos interesses dos sujeitos e grupos sociais envolvidos. Nessa direção, é exemplar a explicitação da influência que se pretendia exercer na formação dos jovens em vários documentos legais da Era Vargas ${ }^{3}$, sobretudo os referentes ao então ensino secundário ${ }^{4}$, pois, conforme o ministro da Educação e Saúde em 1932, Francisco Campos, este nível de ensino seria "o de maior importância", por exercer, "durante a fase mais propícia ao desenvolvimento físico e mental, a sua influência na formação das qualidades da inteligência, do julgamento e do caráter" (CAMPOS, 1932, citado por BETTI, 2009b, p.99). Na época, estabeleceu-se como finalidade da Educação Física no ensino secundário:

[...] proporcionar aos alunos o desenvolvimento harmônico do corpo e do espírito, concorrendo assim para formar o homem de ação, física e moralmente sadio, alegre e resoluto, cônscio de seu valor e das suas responsabilidades (BrasiL, 1938, citado por BETTI, 2009b, p.82).

Evidentemente, os interesses explicitados em relação à Educação Física na Era Vargas guardavam relação com o contexto histórico-político de então, mas compatibilizar ou antagonizar estes discursos político-pedagógicos e as práticas escolares concretas e cotidianas parece ser o grande desafio dos professores de Educação Física em todas as épocas.

Com base na descrição do que fazem os professores de Educação Física e os condicionantes do processo de escolarização (ambos explicitados anteriormente), o próximo passo desse artigo é abordar o problema do conhecimento científico, da sua produção, para o ensino de Educação Física Escolar, orientado pelos seguintes objetivos:

- demarcar o que seja pesquisa em Educação Física Escolar;

- problematizar a pesquisa em Educação Física Escolar no campo mais amplo da pesquisa educacional; 
- caracterizar aspectos da produção bibliográfica em Educação Física Escolar a partir de periódicos científicos nacionais da área da Educação Física;

- apontar direções para as futuras pesquisas em Educação Física Escolar.
Sugerimos que algumas respostas produtivas às questôes que estes objetivos levantam podem ser encontradas no denso ideário sobre a pesquisa educacional legado por J.M.P. Azanha, consubstanciados em dois textos (AZANHA, 1990/1991, 1992).

\section{O que é e o que não é pesquisa em Educação Física Escolar}

A delimitação do que seja pesquisa científica em Educação Física Escolar é uma questão fulcral desse campo de conhecimento. Não é fácil definir ou delimitar o que é pesquisa científica em Educação Física Escolar, pois estamos nos situando numa área de fronteiras um tanto fluidas. Temos aí pelos menos dois problemas: a demarcação do que seja pesquisa científica frente a pesquisa não científica, e a demarcação do que seja pesquisa científica em Educação Física Escolar. Para isso, inicialmente iremos abordar a questão da cientificidade, problematizando a questão no campo mais amplo da pesquisa educacional. Em seguida, iremos focar a própria subárea da Educação Física Escolar para discutir o que seja pesquisa científica específica dessa subárea, uma vez que nem todas as pesquisas científicas que se auto-incluem ou são incluídas, muitas vezes a partir de critérios pouco consistentes, na área da Educação Física escolar poderiam ser de fato assim consideradas, conforme demonstraremos mais adiante.

Existe uma dificuldade inerente em tentar explicitar algum critério ou regra constitutiva do que seja pesquisa científica em Educação Física Escolar. Essa dificuldade é a mesma que vem acompanhando a ciência moderna desde o seu nascimento: o que é conhecimento científico? Há mais de um século vem se buscando um critério objetivo que demarque o conhecimento científico de outros tipos de conhecimento.

Partirmos do pressuposto que não é possível determinar um método ou regra geral que delimite todas as práticas científicas existentes no campo da Educação Física Escolar. Entretanto, AzANHA (1992, p.183), referindo o método científico, ressalta que pode haver métodos incompativeis com a busca da verdade: "aqueles métodos que protegem algumas teorias, hipótese (ou interpretações) no âmbito de uma dada prática científica, porque essa proteção é uma presunção de alcance de verdade e, portanto, de uma razão para a cessação da busca, isto é, da própria prática”.

Com isso Azanha (1992) rejeita uma posição essencialista com relação às propriedades de uma pesquisa científica, assim como a de um relativismo do tipo "tudo pode". O autor propõe encarar a ciência com base numa sistematicidade lógica (não um ideal único de racionalidade) e ressalta: "A rejeição de um ideal absoluto de racionalidade da ciência apenas é o abandono de uma ilusão racionalista e reconhecimento de que diferentes "formas de vida" podem incorporar diferentes formas de racionalidade" (AZANHA, 1992, p.184).

Desse modo, entendemos que é "científica" toda pesquisa que estiver aberta a novas argumentações que possam "tensionar” os princípios, conceitos, afirmações e interpretações que a constituem. Outra característica é que o processo da pesquisa seja público, o que possibilita a sua replicação ou ressignificação por parte de outros atores que não os autores originais da pesquisa. Não pretendemos aplicar de modo exaustivo tal entendimento - que com certeza não é original, está presente nas reflexões de muitos pensadores importantes no âmbito da filosofia da ciência - na análise dos estudos em Educação Física Escolar. A finalidade de sua enunciação é, principalmente, "dispor o terreno" onde se está construindo este texto.

Uma vez que uma pesquisa seja reconhecida como uma pesquisa científica, com base nos apontamentos acima, um desdobramento ou problema possível diz respeito ao foco da pesquisa. Não é incomum encontrarmos pesquisas que elegem como sujeitos os escolares ou profissionais da educação, mas, muitas vezes, a leitura destes trabalhos aponta para outros focos que não o fenômeno "educação escolarizada”. Em publicação original de $1985^{5}$, Lawrence Stenhouse distinguiu a pesquisa sobre educação da pesquisa em educação. Com isso, ele distingue aquelas investigaçôes na História, Psicologia, Sociologia, etc. que apenas secundariamente podem contribuir para a ação educativa nas escolas, pois se orientam pelos paradigmas específicos das respectivas disciplinas, daquelas em que "a investigação realizada dentro do projeto educativo é enriquecedora do empreendimento educativo" (STENHOUSE, 1985, p.42). Mais ainda, o autor aponta que a investigação é educacional se permite em alguma medida relações 
com a prática da educação. Tais relações poderiam estabelecer-se em uma ou mais das seguintes direçôes: 1) uma teoria da pedagogia com algum nível de generalização; 2) uma ampliação da experiência que informa a prática; 3) oferecimento de uma referência para a investigação na ação, quer dizer "um instrumento para explorar as características de determinadas situações" (STENHOUSE, 1985, p.42).

Embora sagaz e provocativa a proposição de Stenhouse nos deixa a dificuldade de definir o que seria a prática de educação, e como dela derivariam objetos de pesquisa que pudesse levar os pesquisadores a efetivamente contribuir para a melhoria das práticas escolares.

Retomamos aqui o diálogo com Azanha em busca de maiores esclarecimentos. Para o autor, os supostos pesquisadores educacionais desconhecem "as relações efetivamente praticadas na escola", e não considera suficiente dizer que "o professor ensina" e "o aluno aprende", e daí pesquisar o "ensino" ou a “aprendizagem” (AZANHA, 1990/1991, p.66). Este entendimento levaria a apenas descrever pobremente as condutas de professores e alunos a partir de objetivos definidos pelas normas legais. Por exemplo, focar a atuação do professor pelo alcance ou não de objetivos prescritos levaria a uma descrição abstrata que apenas permitiria chegar a "uma contabilidade pedagógica que não serve senão para produzir estatísticas escolares", contabilidade na qual "o aluno, na sua realidade social e psicológica, desaparece", porque a atividade do aluno não consiste aí em uma prática escolar, mas é "apenas alvo dela" (AZANHA, 1990/1991, p.66). A mesma distorção ocorreria se tomássemos nessa perspectiva a gestão escolar, o livro didático e etc. Portanto, para Azanha (1990/1991, p.66) o professor, aluno, livro e outros componentes do ambiente escolar são "falsos objetos" que escondem o fundamental: "o jogo das complexas relaçôes sociais que ocorrem no processo institucional da educação"6.

Para esclarecer, AzANHA (1990/1991, p.66-7) exemplifica com o fenômeno da reprovação escolar, alertando que “...o predicado ser reprovado só existe na relação com as práticas que o produziram...”, e, portanto, “...descrever a escola é descrever a formação dessas práticas edos seus correlatos" (...) “...objetivados em mentalidades, conflitos, discursos, procedimentos, hábitos, atitudes, regulamentaçōes, resultados escolares, etc...”.

A crítica de AZANHA (1992) ao processo de descrever no âmbito da pesquisa educacional suporta-se numa distinção entre duas formas de descrição. $\mathrm{O}$ autor distingue uma descrição superficial de uma descrição densa, mas alerta que não há regras muito claras e estabelecidas de antemão para diferenciar uma da outra.
Com base em conhecidos textos de G. Ryle e C. Geertz ${ }^{7}$, Azanha (1992, p.42) depreende que "descrições superficiais são inadequadas para exibir diferenças significativas entre os objetos, isto é, relevantes para conhecimento dos objetos considerados".

De Ryle, AzanHa (1992) toma o exemplo dos "meninos piscantes": dois meninos piscam repetidamente os olhos direitos; em um deles trata-se apenas de uma contração nervosa involuntária, e o outro pisca conspiratoriamente para um cúmplice. De Geertz toma o estudo da briga de galos em Bali: na sociedade balinesa, mais que um passatempo coletivo, a briga de galos cumpre funções sociais muito importantes, que a tornam um "texto cultural”. Descrições densas conseguem distinguir "tiques nervosos de piscadelas conspiratórias, ou brigas de galo em Bali de passatempos coletivos" (AZANHA, 1992, p.163), descrições superficiais pouco acrescentam à compreensão da situação, embora possam apresentar muitos dados.

$\mathrm{Na}$ área da Educação Física é usual falar em "estudos descritivos", mas estamos nos referindo aqui a descrições compreensivas ou interpretativas. Por exemplo, dizer que os alunos do ensino médio desinteressam-se e evadem-se das aulas de Educação Física e apresentar as suas justificativas para tal ("não gosta da aula", "não sabe jogar", etc.) é mera descrição de dados produzidos por respostas dos alunos a questionários ou entrevistas que partem de certos pressupostos valorativos (não participar da aula é "ruim"), e finda por não permitir uma compreensão profunda das relações da conduta de "desinteressar-se e evadir-se" com as práticas escolares que a produziram. Como é preciso apresentar uma “interpretação" dos dados, às vezes os autores fazem inferências sem base nos próprios dados que geraram. Há muitos estudos em Educação Física escolar atravessados por esse equívoco teórico-metodológico.

Retornando ao raciocínio de AzANHA (1990/1991, p.67-8), como a escola é “...uma instituição que possui uma cultura específica com um certo grau de autonomia...”, tal tarefa exige “...um amplo conjunto de investigações (multi e interdisciplinares) capazes de cobrir o amplo espectro das manifestações culturais que ocorrem no ambiente escolar e que se objetivam em determinadas práticas", que não apenas descrevessem estas práticas num dado momento, mas também fossem capazes de identificar e tornar inteligíveis "os processos de sua formação, transformação e permanência”. O acúmulo sistemático dessas descrições permitiria, conforme entende AZANHA (1990/1991) compor um quadro compreensivo da situação escolar, ponto de partida para um esforço 
de explicação e de reformulação, ou em outras palavras do mesmo autor, construir um "mapeamento cultural da escola" (AZANHA, 1990/1991, p.68), do qual se poderiam derivar hipóteses de investigação significativas no campo educacional.

Ao aceitarmos que são estas relações sociais complexas e dinâmicas que envolvem a instituição escolar que constituem o objeto essencial da pesquisa educacional, perguntamo-nos então, junto com AzAnHa (1990/1991), se aqueles que se autoclassificam como pesquisadores em Educação Física Escolar no Brasil têm sido capazes de fazer incidir sobre ele seus esforços investigativos, considerando, evidentemente, a especificidade da disciplina.

Neste ponto, com base em Azanha, já é possível descartarmos o que não é pesquisa em Educação Física Escolar, pois, para a pesquisa educacional não bastaria, somente "caracterizar os protagonistas que atuam no espaço escolar e relacioná-los a condições sociais, políticas e econômicas" conforme (AZANHA, 1990/1991, p.66). Por exemplo, gerar dados que caracterizam em alguns aspectos crianças e jovens (antropométricos, motores, psicológicos, sociais, etc.) apenas como indivíduos que estão incidentalmente presentes nos tempos-espaços escolares não tipifica a pesquisa em Educação Física Escolar, se estes dados não estiverem associados à condição desses sujeitos como alunos no jogo das relaçôes sociais complexas e dinâmicas que envolvem a disciplina "Educação Física" na instituição escolar.

Um exemplo de pesquisa em Educação Física Escolar é o estudo de Oliveira (2010) que subverte a lógica dos estudos predominantes sobre a participação dos alunos nas aulas. $\mathrm{O}$ autor caracterizou o espaço social que denominou "periferia da quadra", situado entre as obrigações escolares e o convívio social mais amplo do aluno na escola, no qual se evidenciou uma rede de sociabilidade, construída a partir de diversos modelos de participação dos alunos nas aulas, que não se esgotam na "prática" das atividades propostas pelo professor. No entendimento do autor, o fenômeno da "periferia da quadra" limita a apropriação dos conhecimentos da Educação Física por parte dos alunos (o que demanda intervenção do professor na situação), mas também lhes permitem formular críticas às aulas, ao professor e à escola, bem como apontar alternativas. Desse modo, podemos constatar que há divergências no modo como professor, de um lado, e alunos, de outro, percebem e avaliam o que é "participar" da aula.

$\mathrm{Na}$ mesma direção, SCHNEIDER e BUENo (2005), com base na teoria da "relação com o saber" de B. $\mathrm{Charlot}^{8}$, apontam divergências entre o que os alunos consideram que aprenderam nas aulas de Educação Física e aquilo que os professores consideram que eles deveriam ter aprendido. Tais divergências relacionam-se com as "figuras do aprender" sugeridas por CHARLOT (2000): aprender pode ser adquirir um saber (no sentido de um conteúdo intelectual, enunciado em linguagem verbal ou escrita), dominar um objeto (usar o computador) ou dominar uma atividade (aprender a nadar), e entrar em formas relacionais (aprender a cumprimentar, a mentir).

Desse modo, Schneider e Bueno (2005), além de detectaram as dificuldades dos alunos em expressar na linguagem escrita o que aprenderam na Educação Física, enfatizam que os saberes abordados pela Educação Física, projetam-se predominantemente no domínio de atividades que demandam controle e uso do corpo, bem como no domínio das formas relacionais. Assim, não seria o caso de "indicar o que os alunos não conseguiram definir como suas aprendizagens em relação aos saberes compartilhados pela Educação Física, mas pedir que demonstrem o que sabem fazer com os objetos, ou quais atividades sabem realizar" (SCHNEIDER \& BUENo, 2005, p.40). Em suma, nos termos colocados por CHARLOT (2000) seria necessário passar de uma "leitura negativa" (o que os alunos não sabem, o que não aprenderam, no que falharam) para uma "leitura positiva" (o que sabem, o que fazem, o que conseguem).

\section{A produção bibliográfica em Educação Física Escolar}

Para analisar as publicações em Educação Física Escolar, utilizamos uma base de dados construída por um dos autores deste artigo. Portanto, os dados aqui apresentados são preliminares.

Selecionamos trabalhos publicados entre 2004 a 2008, em periódicos do campo da Educação Física, classificados no Sistema Qualis na Área 21 da Capes.
Dos 710 periódicos nacionais enumerados na referida Área 21, apenas 28 deles apresentavam na sua política editorial espaço para a subárea de Educação Física Escolar. Posteriormente, este número foi reduzido para 11 , tendo em vista que os demais não atenderam ao critério de inclusão proposto para esta pesquisa - periodicidade regular durante 
pelo menos quatro anos, acessibilidade "on-line" ou no formato impresso na biblioteca da Escola de Educação Física e Esporte da Universidade de São Paulo. A partir desses critérios, foram selecionados os seguintes periódicos:

1) Cinergis (UNISC) - Revista do Departamento de Educação Física e Saúde de Santa Cruz do Sul;

2) Conexões (UNICAMP) - Revista da Faculdade de Educação Física da Universidade de Campinas;

3) Motriz (UNESP) - Revista de Educação Física da Universidade Estadual Paulista Júlio de Mesquita Filho;

4) Movimento e Percepção (UNIPINHAL) Revista do Curso de Educação Física do Centro Regional Universitário do Espírito Santo do Pinhal;

5) Movimento (UFRGS) - Revista da Escola de Educação Física da Universidade Federal do Rio Grande do Sul;

6) Pensar a Prática (UGF) - Revista da Faculdade de Educação Física da Universidade Federal de Goiás;

7) Revista Brasileira de Ciência e Movimento (CELAFISCS e UCB) - Revista do Centro de Estudos do Laboratório de Aptidão Física de São Caetano do Sul e da Universidade Católica de Brasília;

8) Revista Brasileira de Ciências do Esporte - Revista do Colégio Brasileiro de Ciências do Esporte;

9) Revista Brasileira de Educação Física e Esporte (USP) - Revista da Escola de Educação Física e Esporte da Universidade de São Paulo;

10) Revista da Educação Física (UEM) - Revista brasileira da Escola de Educação Física da Universidade Estadual de Maringá;

11) Revista Mackenzie de Educação Física e Esporte - Revista da Faculdade de Educação Física da Universidade Presbiteriana Mackenzie.

Foram encontrados nessas revistas 1.582 artigos, classificados inicialmente em duas categorias: escolar e não escolar. Em seguida, os artigos classificados como escolar foram subclassifcados com base em três critérios distintos: ciclos de escolarização, práticas corporais investigadas e temas.

Uma classificação inicial para distinguir os trabalhos específicos de Educação Física Escolar foi feita por um professor universitário envolvido com o ensino e pesquisa nesse campo acadêmico e com experiência de 13 anos como professor de Educação Física Escolar. O principal critério utilizado para discriminar os artigos foi a natureza do objetivo da pesquisa explicitado no resumo e/ou no corpo do artigo. O segundo critério está baseado na distinção, já aqui mencionada, feita por STENHOUSE (1985), entre pesquisa sobre educação e pesquisa em educação. Dos 1.582 artigos publicados nas revistas selecionados, 1.293 (82\%) foram classificados como "não Educação Física Escolar" e 289 (18\%) como "Educação Física Escolar". Esse resultado era esperado, uma vez que todas as revistas possuem um caráter "genérico", isto é, possuem uma política editorial voltada para divulgação de conhecimento de um amplo espectro de subáreas da Educação Física - Biodinâmica, Sociocultural e Pedagógica. A única exceção é a Revista Movimento que tem uma proposta editorial voltada exclusivamente para as subáreas Sociocultural e Pedagógica. O resultado é semelhante ao encontrado por ANTUNES, DANTAS, Bigotti, Tokuochi, Tani, Kundrat e André (2005), que utilizaram uma base de dados similar, porém delimitando o período 1999-2003, e identificaram $78,8 \%$ dos artigos como "não Educação Física Escolar" e 21,2\% dos artigos como de "Educação Física Escolar".

Para os ciclos de escolarização partiu-se da proposição da Lei de Diretrizes e Bases da Educação (BRASIL, 1996) que estabelece: educação infantil, ensino fundamental, ensino médio, educação superior (Capítulo I - Dos Níveis e das Modalidades de Educação e Ensino - Art. $21^{\circ}$.) e educação de jovens e adultos - EJA (Capítulo 1, Seção V, Art.37o: "é destinada àqueles que não tiveram acesso ou continuidade de estudos no ensino fundamental e médio na idade própria”). Além disso, incluíram-se, na análise, as categorias "formação continuada" e "ciclo não definido". No caso da formação continuada foram consideradas nesta categoria pesquisas que investigaram o período após a formação inicial. A categoria ciclo não definido refere-se aos estudos sobre Educação Física Escolar que não especificaram um ciclo de escolarização, remetendo-se a educação básica em geral.

Os resultados da análise encontram-se na TABELA 1:

TABELA 1 - Frequência de estudos relacionados aos ciclos de escolarização da educação básica, do ensino superior, da formação continuada e da educação de jovens e adultos.

\begin{tabular}{lc}
\hline \multicolumn{1}{c}{ CICLOS } & No. de Estudos (\%) \\
\hline Educação infantil & $28(9,2 \%)$ \\
Ensino fundamental & $87(28,7 \%)$ \\
Ensino médio & $30(9,9 \%)$ \\
Ensino superior & $39(12,9 \%)$ \\
Formação continuada & $24(7,9 \%)$ \\
Educação de jovens e adultos & $2(0,7 \%)$ \\
Não definido & $95(31,4 \%)$ \\
\hline Total * & $303(100 \%)$ \\
\hline
\end{tabular}

* Um artigo pode abranger mais do que um ciclo de escolarização. 
Observa-se na TABELA 1 que os estudos estão distribuídos por todos os ciclos, mas com forte incidência no Ensino Fundamental de um lado, e raros estudos na Educação de Jovens e Adultos - EJA. Todavia, o EJA constitui uma demanda importante de investigação, uma vez que nele estavam matriculados, em 2010, 4,2 milhóes de alunos (MEC, 2010).

Em relação a análise sobre as práticas corporais que foram objeto de investigação, de um total de 283 artigos analisados, 216 não se referiam a qualquer tipo de prática. A seguir, conforme apresenta a TABELA 2 , os 67 artigos que investigavam práticas corporais foram submetidos a uma categorização amplamente utilizada na recente literatura acadêmica e profissional da área de Educação Física, a saber: jogo, esporte, dança, ginástica, luta e outros. A diferenciação entre as categoria "jogo" e "esporte" decorreu da existência ou não de uma prática fortemente influenciada pelo modelo do esporte formal-federativo. A categoria denominada "outros" refere-se a manifestaçôes como: atividades circenses, "parkour", "skate”, etc.

TABELA 2 - Frequência de práticas corporais investigadas.

\begin{tabular}{lc}
\hline \multicolumn{1}{c}{ PRATICAS CORPORAIS } & No. de Estudos (\%) \\
\hline Jogo & $33(40,2 \%)$ \\
Esporte & $22(26,8 \%)$ \\
Ginástica & $10(12,1 \%)$ \\
Dança & $10(12,1 \%)$ \\
Lutas & $5(6,1 \%)$ \\
Outros & $2(2,4 \%)$ \\
\hline Total & $82(100 \%)$ \\
\hline
\end{tabular}

*Um artigo pode investigar mais de uma prática corporal.

Os resultados indicam que a produção bibliográfica distribui-se por todas as práticas, porém muito concentradas (67\%) no binômio "Jogo-Esporte". De certa maneira, tal concentração reflete a tradição das práticas pedagógicas da Educação Física Escolar em nosso país. Contudo, também indica um descompasso em relação às teorizações hegemônicas atualmente, fundadas nos conceitos de cultura corporal (CAStellani Filho, Soares, Taffarel, Varjal, Escobar \& BRACHT, 2009) ou cultura do movimento (KunZ, 1991) , ou ainda cultura corporal de movimento (BЕтTI, 2009a), que indicam à Educação Física Escolar a necessidade de trabalhar uma diversidade de manifestações culturais ligadas ao corpo e ao movimento. Tal desequilíbrio pode ser visto como um indicador da premência de estudos que contemplem as outras manifestações (dança, lutas, ginástica e outras) sob o risco, inclusive, de inviabilizar a implementação de propostas curricular apresentadas em diversos Estados e municípios brasileiro nos últimos anos.

Em relação aos temas investigados, os artigos de "escolar" foram subclassifcados em seis categorias, ligeiramente adaptado do que foi proposto por ANTUNES et al. (2005). Estas são as categorias aqui propostas:

a) Finalidade - investigação sobre os fins, objetivos e sentidos da disciplina Educação Física Escolar (proposição, compilação ou análise das suas finalidades e implicaçôes);

b) Caracterização - descrição das aulas de Educação Física, em suas dimensões física psicológica, comportamental, histórica, social e etc., assim como seus entrelaçamentos com aspectos individuais, coletivos no contexto da escola e em contextos sociais mais amplos. Essa categoria é representada por pesquisas de cunho descritivo-interpretativo;

c) Didática - estudo dos fatores e métodos envolvidos na otimização dos processos de ensino e aprendizagem;

d) Formação de professores - pesquisa sobre o processo de formação de professores em todas as suas modalidades;

e) Epistemologia - investigação sobre a natureza do conhecimento do campo da Educação Física Escolar, ou seja, o estudo dos postulados, conclusóes e métodos de pesquisa das diferentes subáreas do campo da Educação Física Escolar;

f) Indefinido - investigações em que não é possível identificar um tema central, ou quando aparece mais de um tema entre os anteriormente mencionados, sem predominância identificável.

Em uma classificação ainda preliminar, a TABELA 3 apresenta a distribuição dos trabalhos pelos temas no período em foco neste artigo (2004-2008), comparando-o com período anterior (1999-2003), conforme dados de ANTUNEs et al. (2005), que analisaram apenas seis periódicos (revistas), todas elas incluídas no nossa própria análise.

TABELA 3 - Frequência dos temas investigados.

\begin{tabular}{|c|c|c|c|}
\hline TEMA & 2004-2008 & 1999-2003 & * No estudo de AntunES \\
\hline Caracterização & $171(59 \%)$ & $50(39 \%)$ & $\begin{array}{l}\text { et al. (2005), denomina- } \\
\text { da "Processo Ensino- }\end{array}$ \\
\hline Didática* & $57(20 \%)$ & $15(11,8 \%)$ & Aprendizagem" \\
\hline Formação de professores & $23(8 \%)$ & $19(15 \%)$ & \\
\hline Finalidades & $22(8 \%)$ & $26(20 \%)$ & \\
\hline Epistemologia & $5(2 \%)$ & $5(3,9 \%)$ & \\
\hline Indefinido & $5(2 \%)$ & $12(9,4 \%)$ & \\
\hline Total & $283(100 \%)$ & $127(100 \%)$ & \\
\hline
\end{tabular}


Três aspectos chamam a atenção na TABELA 3: o aumento dos estudos que buscam caracterizar aspectos da realidade escolar, o aumento de estudos em didática e a diminuição dos estudos com a temática das finalidades da Educação Física.

Inicialmente, em relação aos estudos de orientação descritiva (caracterização da realidade escolar) o aumento dessa categoria deve ser visto com cautela. Não sabemos se a maioria destes estudos são "descriçõos compreensivas e interpretativas" ou descriçōes superficiais. Outro aspecto importante a respeito destas descrições é verificarmos se estes estudos permitem "em alguma medida relações com a prática da educação"; ou seja, se são pesquisas "em" Educação Física Escolar.

A duplicação da porcentagem de estudos com o tema da didática pode ser um reflexo da crescente reivindicação do campo profissional por subsídios para a prática pedagógica (ver CAPARROZ \& BRACHT,

\section{Conclusões}

O diagnóstico e análises que aqui empreendemos, evidentemente não exaustivos, nos levam a apontar algumas direções para que as investigações em Educação Física Escolar tornem-se mais significativas. E por "significativas" queremos dizer pesquisas que delimitem suas problemáticas tendo como referência, retomando as palavras de AZANHA (1990/1991, p.66-7) "o jogo das complexas relaçôes sociais" das práticas pedagógicas da Educação Física, que de fato busquem "descrever a formação dessas práticas e dos seus correlatos (...) objetivados em mentalidades, conflitos, discursos, procedimentos, hábitos, atitudes, regulamentaçôes, resultados escolares, etc."

A primeira indicação é que o foco na "didática" é estratégico, pois possibilita articular os diversos temas de pesquisa em direção às práticas pedagógicas concretas, diagnosticar equívocos e méritos dos processos de ensino e aprendizagem vigentes, e apontar novas possibilidades de intervenção. Dado as especificidade de cada ciclo de escolarização, entendemos como muito importante que as pesquisas dêem suporte para a construção de didáticas específicas para a Educação Infantil e o Ensino Médio, que tem sido preteridos, como também o EJA, em favor do Ensino fundamental. Do mesmo modo, a literatura didático-pedagógica ainda carece de enfoques específicos que orientem com maior qualificação científica o ensino da luta, da ginástica e da dança.
2007). Isto pode ser visto como os primeiros indícios de uma resposta ao "atrofiamento" das pesquisas em didática que a área experimentou nas últimas duas décadas.

Nos últimos anos temos constatado a proposição de inúmeros programas de Educação Física nos sistemas públicos de ensino (municipal, estadual e federal). De certa forma, houve um deslocamento deste tipo de discussão do contexto acadêmico para o contexto das políticas públicas. Isto pode ser uma explicação para a diminuição dos estudos sobre as finalidades da Educação Física Escolar. Esse esvaziamento pode tanto ser visto com um avanço - uma vez que no atual momento parece mais profícuo investir em estudos que investiguem a implantação desses programas - ou como um alerta, no sentido de que houve um esgotamento do paradigma hegemônico no debate, havendo necessidade de introdução de novas perspectivas teóricas.

A segunda diz respeito aos programas (currículos) de Educação Física propostos em vários níveis das políticas públicas de educação em nosso país. Tem sido comuns as críticas endereçadas a estas propostas, no sentido de que elas estariam ferindo as autonomias das escolas e dos professores, ao supostamente padronizarem conteúdos e desconsiderarem os contextos locais.

Sem menosprezar tais críticas, chamamos atenção para a advertência de AzANHA (1990/1991, p.68) sobre o tema, para quem "Os estudos sobre políticas e reformas educacionais brasileiras têm sido, sobretudo, monotonamente polêmicos ou até mesmo julgamentos ideológicos". A consequência, entende o autor, é que, a cada nova reforma, não há dados científicos confráveis sobre as repercussões das reformas anteriores. Por isso, sugere então que a pesquisa educacional dedique-se a compreender as reformas "desde as decisóes políticas que as instituem legalmente, passando pelas providências técnico-administrativas de vários níveis que as regulamentam, até as práticas escolares que deveriam implantá-las" (AZANHA, 1990/1991, p.69).

Nessa direção, também concordamos com BETTI, Daólio, Venâncio e Sanches Neto (2010), a respeito das consideraçóes que fizeram sobre a Proposta Curricular de Educação Física do Estado de São Paulo (SÃo Paulo, 2008), implementada a partir de 2008 em cerca de 4.200 escolas públicas estaduais. 
Para os autores, avaliar de modo consistente essa proposta, ou qualquer outra proposta curricular, exige investigar, de modo rigoroso, como os docentes "lidam com propostas de mudança curricular, como seus saberes profissionais intervêm nesse processo [...] assim como, se, e em que direção, essas inovaçôes têm propiciado melhorias nas aprendizagens dos alunos" (BЕTTI et al., 2010, p.126). Portanto, os temas da autonomia dos professores e das escolas, dos saberes docentes e da qualidade da aprendizagem dos alunos deverão estar em relevo nas futuras pesquisas em Educação Física Escolar.

A terceira e última indicação aponta para os estudos sobre a formação do professor (licenciado) de Educação Física que prosseguem sendo indispensáveis, pois, a responsabilidade dos professores nos empreendimentos educativos é diferenciada em relação aos demais atores escolares, pois são os que cotidianamente relacionam-se com os alunos e a eles propóem modos de acesso à cultura, por meio dos conteúdos escolares. Por isso, as investigaçōes sobre o projeto político pedagógico e o "currículo oculto" das instituiçỗes de ensino superior são indispensáveis para compreendermos como se dá a formação dos licenciados, instância que, afinal, põe os futuros professores em contato inicial com os conhecimentos científicos e com as práticas profissionais da área.
E é apresentando um dado geral (e preocupante) sobre a produção acadêmica nos cursos de doutorado em Educação Física no Brasil que encerramos este artigo. Segundo Nascimento (2010), de 1994 a 2008, as seis universidades que à época da realização do levantamento contavam com o nível de doutorado na área somaram 333 teses defendidas. A presença relativa da Educação Física Escolar como temática dos trabalhos é minoritária $(6,3 \%)$ variando entre zero teses (USP, UNESP/Rio Claro e UCB) e 16 teses (UNICAMP).

Se admitirmos que o doutorado é o nível de formação que melhor habilita academicamente os docentes para o exercício do ensino e da pesquisa na educação superior, independentemente de qualquer parâmetro de comparação quantitativo impõe-se admitir que a pós-graduação em Educação Física no Brasil pouco tem investido nas pesquisas em Educação Física Escolar. Os fatores que levaram a esta situação são inúmeros e complexos, e sua análise foge aos objetivos específicos deste artigo. Todavia, é urgente revertê-la, sob pena de, a médio prazo, comprometer a qualidade pedagógica da Educação Física Escolar e assim minimizar, para relembrar nossas palavras iniciais, a riqueza "dos sentidos culturais e potencialidades de estimulação do organismo humano" que este componente curricular pode oferecer à formação das crianças, jovens e adultos.

\section{Notas}

1. SILVA, J.B.F. As relaçôes entre o fazer e o compreender na prática da Educação Física. 1982. 161 f. Dissertação (Mestrado em Educação Física) - Escola de Educação Física, Universidade de São Paulo, São Paulo, 1982

2. Por exemplo, é possível caracterizar, na atualidade, manifestaçōes como a capoeira, o "parkour" ou "le parkour" (e outras modalidades dos denominados "esportes radicais" ou "esportes de aventura"), que questionam a tradição da Educação Física, e só com certa dificuldade se deixam classificar nas categorias pré-estabelecidas do jogo, esporte, luta, dança e ginástica.

3. A "Era Vargas" refere-se a um período contínuo de 15 anos (1930-1945), em que Getúlio Vargas governou o Brasil.

4. Equivalente, hoje, ao segundo ciclo do ensino fundamental e parte do ensino médio.

5. STENHOUSE, L. Research as a basis for teaching. Londres: Heinemann Educational, 1985.

6. O destaque é nosso.

7. RYLE, G. Colleted papers. London: Hutchinson, 1971. v.2.; GEERTZ, G. A interpretação das culturas. São Paulo: LTC, 1989.

8. Bernard Charlot, filósofo e pedagogo francês, foi professor da Universidade de Paris, atualmente radicado no Brasil, é professor visitante na Universidade Federal de Sergipe. 


\begin{abstract}
School Physical Education: present state and future directions

The aim of this paper is to characterize and discuss the School Physical Education as a profession and subarea of research in the broader academic field of Physical Education and educational research. To do that, it initially defines the difference between research in School Physical Education from research about School Physical Education, and point out the themes and research hypotheses for this subarea. It also analyses 289 articles characterized as research in School Physical Education, published in 11 Brazilian periodicals, classifying them in the following categories: "level of schooling", "bodily practice" and "theme". The results indicate that the majority of studies are carried out in elementary school, in "games" and "sports", and in descriptive and interpretative research in School Physical Education practices in several dimensions and interrelations. In conclusion, it points to the need to a focus in the research in teaching, the implementation of public curricula, and teacher education. Finally, it alerts to the need for Brazilian postgraduate programs in the academic field of physical education to invest more in research in School Physical Education subarea.
\end{abstract}

UnItERMs: Physical Education; Profession; Teaching; Scientific Research.

\title{
Referências
}

ANTUNES, F.H.C.; DANTAS, L.E.P.B.T.; BIGOTTI, S.; TOKUOCHI, J.H.;TANI, G.; KUNDRAT, F.; ANDRE, M. Um retrato da pesquisa brasileira em educação física escolar: 1999-2003. Motriz, Rio Claro, v.11, n.3 p.179-84, 2005.

AZANHA, J.M.P. A cultura escolar brasileira: um programa de pesquisas. Revista da USP, São Paulo, n.8, p.65-9, 1990/1991. AZANHA, J.P. Uma idéia de pesquisa educacional. São Paulo: Editora da USP, 1992.

BETTI, M. Educação física escolar: ensino e pesquisa-ação. Ijuí: Unijuí, 2009a.

Educação física e sociedade: a educação física na escola brasileira. 2a. ed. São Paulo: Hucitec, 2009b.

BETTI, M.; DAOLIO, J.; VENANCIO, L.; SANCHES NETO, L. A proposta curricular de educação física do Estado de São Paulo: fundamentos e desafios In: CARREIRA FILHO, D.; CORREIA, W.R. (Orgs.). Educaçáo física escolar: docência e cotidiano. Curitiba: CRV, 2010. p.109-28.

BRACHT, V. Educação física: a busca da legitimação pedagógica. In: ___ _ Educação física e aprendizagem social. Porto Alegre: Magister, 1992. p.33-53.

BRASIL. Congresso. Lei no 9.394, de 20 de dezembro de 1996. Estabelece as diretrizes e bases da educação nacional. Brasília: Congresso Nacional, 1996. Disponível em: <http://www.planalto.gov.br/ccivil_03/Leis/L9394.htm>. Acesso em: 21 jun. 2011

Lei no 9.394, de $\mathbf{1}^{\circ}$ de dezembro de 2003. Altera a redação do art. 26, $₫$ 3o, e do art. 92 da Lei no 9.394, de 20 de dezembro de 1996, que "estabelece as diretrizes e bases da educação nacional”, e dá outras providências. Brasília: Congresso Nacional, 2003. Disponível em: <http://www.planalto.gov.br/ccivil_03/Leis/2003/L10.793.htm>. Acesso em: 21 jun. 2011.

BRASIL. Ministério da Educação/INEP. Censo Escolar. Brasília: MEC/INEP, 2010.

CAPARROZ, F.E.; BRACHT, V. O tempo e o lugar de uma didática da educação física. Revista Brasileira de Ciências do Esporte, Campinas, v.28., n.2, p.21-37, 2007.

CASTELLANI FILHO, L.; SOARES, C.L.; TAFFAREL, C.N.Z.; VARJAL, E.; ESCOBAR, M.O.; BRACHT, V. Metodologia do ensino de educação física. 2a. ed. São Paulo: Cortez, 2009.

CHARLOT, B. Da relação com o saber: elementos para uma teoria. Porto Alegre: ArtMed, 2000.

KUNZ, E. Educação física: ensino \& mudanças. Ijuí: Unijuí, 1991.

NASCIMENTO, A.C.S. Mapeamento temático das teses defendidas nos programas de pós-graduação em educação física no Brasil (1994-2008). 2010. 278 f. Tese (Doutrado em Ciência da Informação) - Escola de Comunicação e Artes, Universidade de São Paulo, São Paulo, 2010.

OLIVEIRA, R.C. Na “periferia” da quadra: educação física, cultura e sociabilidade na escola. 2010. 201f. Tese (Doutorado em Educação Física) - Faculdade de Educação Física, Universidade Estadual de Campinas, Campinas, 2010.

114 • Rev. bras. Educ. Fís. Esporte, São Paulo, v.25, p.105-15, dez. 2011 N. esp. 
ROSA, S.; LETA, J.Tendências atuais da pesquisa brasileira em educação física - parte 1: uma análise a partir de periódicos nacionais. Revista Brasileira de Educação Física e Esporte, São Paulo, v.24, n.1, p.121-34, 2010.

. Tendências atuais da pesquisa brasileira em educação física - parte 2: a heterogeneidade epistemológica nos programas de pós-graduação. Revista Brasileira de Educação Física e Esporte, São Paulo, v.25, n.1, p.7-18, 2011.

SÃO PAULO (Estado). Secretaria da Educação. Proposta curricular do Estado de São Paulo: educação física - ensino fundamental ciclo II e ensino médio. São Paulo: SEE, 2008. Disponível em: <http://www.rededosaber.sp.gov.br/portais/ Portals/18/arquivos/Prop_EDF_COMP_red_md_20_03.pdf >. Acesso: 20 jul. 2011.

SCHNEIDER, O.; BUENO, J.G.S. A relação dos alunos com os saberes compartilhados nas aulas de educação física. Movimento, Porto Alegre, v.11, n.1, p.23-46, 2005.

STENHOUSE, L. La investigación como base de la ensenãnza. 2a. ed. Madrid: Morata, 1993.

ENDEREÇO

Mauro Betti

Departamento de Educação Física

Faculdade de Ciências

Universidade Estadual Paulista - Campus Bauru

Av. Eng. Luiz E. Carrijo Coube, s/ $\mathrm{n}$

17033-360 - Bauru - SP - BRASIL e-mail: mbetti@fc.unesp.br 